\title{
Computerized tomography evaluation of a resorbable implant after transforaminal lumbar interbody fusion
}

\author{
Timothy R. Kuklo, M.D., J.D., Michael K. Rosner, M.D., \\ AND DAVID W. Polly JR., M.D. \\ Department of Orthopaedics and Rehabilitation, Walter Reed Army Medical Center, Washington, DC; \\ Uniformed Services University of the Health Sciences, Bethesda, Maryland; and Department of \\ Orthopaedic Surgery, University of Minnesota, and Twin Cities Spine Center, Minneapolis, Minnesota
}

\begin{abstract}
Object. Synthetic bioabsorbable implants have recently been introduced in spinal surgery; consequently, the indications, applications, and results are still evolving. The authors used absorbable interbody spacers (Medtronic Sofamor Danek, Memphis, TN) packed with recombinant bone morphogenetic protein (Infuse; Medtronic Sofamor Danek) for single- and multiple-level transforaminal lumbar interbody fusion (TLIF) procedures over a period of 18 months. This is a consecutive case series in which postoperative computerized tomography (CT) scanning was used to assess fusion status.

Methods. There were 22 patients (17 men, five women; 39 fusion levels) whose mean age was 41.6 years (range 23-70 years) and in whom the mean follow-up duration was 12.4 months (range 6-18 months). Bridging bone was noted as early as the 3-month postoperative CT scan when obtained; solid arthrodesis was routinely noted between 6 and 12 months in 38 (97.4\%) of 39 fusion levels. In patients who underwent repeated CT scanning, the fusion mass appeared to increase with time, whereas the disc space height remained stable. Although the results are early (mean 12-month follow-up duration), there was only one noted asymptomatic delayed union/nonunion at L5-S1 in a twolevel TLIF with associated screw breakage. There were no infections or complications related to the cages.

Conclusions. The bioabsorbable cages appear to be a viable alternative to metal interbody spacers, and may be ideally suited to spinal interbody applications because of their progressive load-bearing properties.
\end{abstract}

\section{KEY WORDS • bioabsorbable implant • polylactide polymer • bone morphogenetic protein • lumbar fusion • computerized tomography}

Structural interbody support has become a well-accepted component in the armamentarium for spinal fusion. First advocated by Steffee and widely popularized by Harms, this can be accomplished via the ALIF, PLIF, or more recently via the TLIF procedure. Structural interbody support with titanium surgical mesh in combination with posterior instrumentation has been shown to yield biomechanically superior results. Furthermore, titanium surgical mesh has performed well to date in many centers, but there are still problems with imaging artifacts, potential for late implant infection, and persistent stress shielding of the fusion mass bone.

Bioabsorbable implants appear to possess the ideal characteristics of an interbody fusion device. They provide immediate postoperative stability but permit controlled load sharing over time through resorption. ${ }^{24}$ Furthermore, there appears to be no significant inflammatory response or foreign body reaction, ${ }^{21}$ which can lead to

Abbreviations used in this paper: ALIF = anterior lumbar interbody fusion; $\mathrm{BMP}=$ bone morphogenetic protein; $\mathrm{CT}=$ computerized tomography; PLIF = posterior lumbar interbody fusion; rhBMP-2 = recombinant human BMP-2; TLIF = transforaminal lumbar interbody fusion; $3 \mathrm{D}=$ three-dimensional. sterile abscess formation and/or an increased infection rate. ${ }^{5}$ In addition, fusion status is easily assessed because of the radiolucent nature of the implant.

The advantages of BMP are also well known and include decreased operating time and blood loss compared with iliac crest harvesting, decreased morbidity, and perhaps increased fusion rates. The efficacy of rhBMP-2 in interbody fusions has been reported previously in animal models and preliminarily in controlled studies. ${ }^{19}$ Nevertheless, few clinical studies regarding the use of bioabsorbable implants packed with rhBMP-2 have been reported. The use of BMP may also have the added advantage of decreased infection rates, as seen in the trial of its use in open tibia fractures. ${ }^{12}$

\section{CLINICAL MATERIAL AND METHODS}

\section{Patient Population}

Over the past 18 months, 35 patients have undergone a single- or multiple-level TLIF (mean 1.7 levels, range 1-5 levels) at our institution with implantation of absorbable cages and segmental pedicle screw fixation with titanium multiaxial pedicle screws and 5.5-mm-diameter rods. Of 
these patients, 22 had at least a 6-month follow-up duration and are the focus of this paper. There were 17 men and five women whose mean age was 41.6 years (range 23-70 years) and in whom the mean follow-up duration was 12.4 months (range 6-18 months).

The most common diagnoses were degenerative disc disease and isthmic spondylolisthesis (Table 1). Four cases involved revision surgeries, whereas two were for failed-back syndrome. Six of the 22 patients were known smokers. In addition to the standard clinical follow-up review, immediate postoperative $\mathrm{CT}$ scans and standing plain radiographs were obtained in all patients. Plain radiographs were also obtained at 6 weeks, at 3, 6, and 12 months and at the latest follow-up review. The CT scans were obtained at 6,12 , and/or 18 months as appropriate to assess fusion status.

Radiographs were evaluated for instrumentation complications, disc height, and evidence of bridging bone in the interbody space. The CT scans in which sagittal and coronal 3D reconstruction was used were evaluated for bridging bone in the interbody space as well as evidence of dislodgment, subsidence, and/or a sterile abscess or reactive zone around the implant.

\section{Resorbable Interbody Cages}

All procedures in this series were performed using the bioabsorbable noncrystalline copolymer implant HYDROSORB (Medtronic Sofamor Danek, Memphis, TN), which has a 70:30 ratio of poly(L-lactide) to poly(D,Llactide). The device made from this material has an elastic modulus of $3.15 \mathrm{GPa}$, an ultimate compressive strength of $100 \mathrm{MPa}$, an ultimate tensile strength of $58 \mathrm{MPa}$, and a ductility of 5\% elongation to failure (Fig. 1). ${ }^{11}$ It can withstand a compressive load to failure of $8230 \mathrm{~N}$ after sterilization, which exceeds the load necessary to crush most vertebral bodies. ${ }^{21}$ It degrades by surface dissolution and does not form crystalline degradation products. ${ }^{14}$ This racemic form has significantly reduced the incidence of sterile abscess formation and the concerns about infection that were first noted during the early attempts to use bioabsorbable materials on long-bone fractures ${ }^{4,5}$ In fact, the breakdown products incorporate into normal cellular products because the implant degrades uniformly. ${ }^{22}$ Therefore, there are no immunogenic or mutagenic tendencies. ${ }^{8}$

The HYDROSORB cages come in various heights $(5-20 \mathrm{~mm})$ and in various diameter configurations $(11,13$, 19 , and $26 \mathrm{~mm}$ ). The wall thickness is a standard $2 \mathrm{~mm}$ for the smaller-diameter components, and $4 \mathrm{~mm}$ for the 19and 26- $\mathrm{mm}$ components. Insertion is completed using a

TABLE 1

Preoperative diagnoses in 22 patients treated with bioabsorbable implants

\begin{tabular}{lc}
\hline \hline \multicolumn{1}{c}{ Diagnosis } & No. of Patients (\%) \\
\hline degenerative disc disease & $6(27.3)$ \\
isthmic spondylolisthesis & $5(22.7)$ \\
adult degenerative scoliosis & $4(18.2)$ \\
degenerative spondylolisthesis & $4(18.2)$ \\
failed-back syndrome & $2(9.1)$ \\
congenital scoliosis & $1(4.6)$ \\
\hline
\end{tabular}

specialized straight or angled inserter. In this study, the typical implant was 11 or $13 \mathrm{~mm}$ in diameter and approximately $9 \mathrm{~mm}$ in height (range $5-11 \mathrm{~mm}$ height), depending on the vertebral level and diagnosis. Routinely, the implants were placed in a unilateral fashion via a transforaminal approach, but they can obviously be placed via a bilateral, PLIF, or ALIF approach. Degradation occurs over 18 to 36 months, with a minimum of $50 \%$ of the initial structural strength maintained at 1 year postoperatively. ${ }^{9}$ The implant is also well visualized on CT scans prior to degradation. Nonetheless, some degradation is still influenced by host conditions, as well as by the implant size and geometry. ${ }^{1}$

\section{Bone Morphogenetic Protein-2}

All procedures were also completed using rhBMP-2, which was packed into the cages before insertion. A standard small Infuse bone graft collagen sponge (Medtronic Sofamor Danek) is adequate for a single-level TLIF completed with two interbody spacers. In most cases, part of the sponge was placed anteriorly to the two cages as well. Nevertheless, a large collagen sponge is more cost effective when performing a fusion at two or more levels, because a single large kit can adequately cover a two-level interbody fusion. A cost analysis of BMP in spinal fusion has previously been published. ${ }^{17}$

\section{RESULTS}

Eight single-level and 14 multiple-level (two-five levels) fusions were performed (39 fusion levels, Table 2). The mean operating time was 4.2 hours (range 2.25-8.9 hours) or 2.3 hours per fusion level (range 2.25-3.8 hours/ level). The mean blood loss was $380 \mathrm{ml}$ (range 150-800 $\mathrm{ml}$ ) or $223.5 \mathrm{ml}$ per level. The mean hospital stay was 4.7 days (range 3-9 days). Although there was no control group in this study, these parameters appear to be less than or consistent with those in previously reported series. ${ }^{6}$ There were also 15 active-duty soldiers in the study, all of whom remained on active duty at the last follow up.

There were no infections, allergic reactions, deep venous thromboses, or implant complications. There were three postoperative neurological changes, however, two of which were considered to be transient neurapraxia or mild motor weakness that was considered secondary to nerve root retraction at the operative level. Both of these deficits resolved within 6 weeks postoperatively. This is a fairly common finding after TLIF procedures ${ }^{13}$ (Table 3), and the changes were not considered to be secondary to the position or insertion of the implant. The third neurological postoperative change was a persistent right-sided L-5 neurodynia, which also occurred at the operative level in an L4-S1 two-level TLIF for Grade II L5-S1 spondylolisthesis treated with partial reduction. At 6 months postoperatively, this patient underwent a selective L5-S1 foraminal decompression, which relieved the radiculopathy. There was also one intraoperative dural tear, which was primarily repaired without sequelae. There were no complications related to the resorbable cages or rhBMP-2.

\section{Radiographic Findings}

Standing lateral plain radiographs were evaluated for 

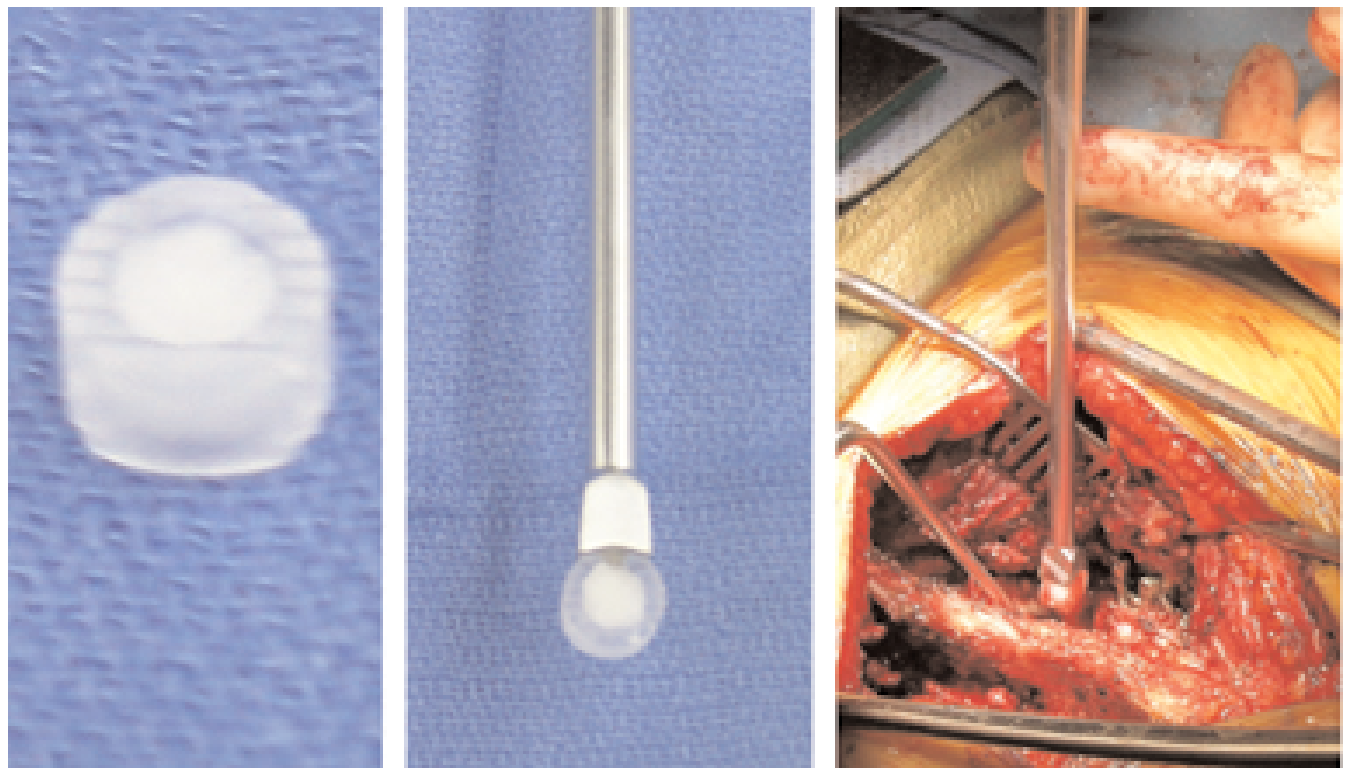

Fig. 1. Left: Photograph showing a HYDROSORB cage packed with rhBMP-2 on a collagen sponge placed in the center of the implant. Center: Photograph showing a HYDROSORB cage packed with rhBMP-2 and loaded on the inserter. Right: Intraoperative photograph showing the HYDROSORB cage being placed with inserter during the TLIF procedure.

instrumentation complications, posterior disc height, and evidence of bridging bone in the interbody space. All measurements were performed on a digital PAX machine (Siemens AG, Karlsburg, Germany) equipped with digital calipers accurate to $0.01 \mathrm{~mm}$. One broken screw was found in a 33-year-old man who underwent an L4-S1 two-level TLIF for chronic back pain caused by degenerative disc disease (Fig. 2). At the 1-year follow-up visit he was asymptomatic and appeared to have a solid arthrodesis on CT scanning. He is also a smoker. There were no other instrumentation complications.

The mean preoperative disc height at each treated level (39 levels), measured at the posterior vertebral corner, was $5.2 \mathrm{~mm}$ (range $2.5-8.5 \mathrm{~mm}$ ). In the case of spondylolisthesis, a tangential line along the inferior vertebral body was projected posteriorly to depict the estimated disc height without listhesis. Measured on standing radiographs obtained immediately postoperatively, the mean treated disc space height was $8.6 \mathrm{~mm}$ (range 4.5-10.5 $\mathrm{mm}$ ), or $+3.3 \mathrm{~mm}$ (range +2 to $5.8 \mathrm{~mm}$ ). At the 3 -month follow-up review, the mean disc height was $8.2 \mathrm{~mm}$ (range $4.4-10.5 \mathrm{~mm}$ ), possibly indicating slight settling of the implant; however, this difference was not statistically significant $(\mathrm{p}=0.31)$. At the last follow-up review (mean

TABLE 2

Number of TLIFs performed at each level

\begin{tabular}{lc}
\hline \hline Level & No. at Level \\
\hline L1-2 & 1 \\
L2-3 & 2 \\
L3-4 & 5 \\
L4-5 & 13 \\
L5-S1 & 18 \\
total & 39 \\
\hline
\end{tabular}

12.4 months), the mean posterior disc height was unchanged at $8.1 \mathrm{~mm}(\mathrm{p}=0.42)$.

The bioabsorbable cages are not visualized on plain radiographs; therefore, the interbody fusion status can be accurately assessed. We considered $34(87.2 \%)$ of 39 fusion levels to have a solid arthrodesis of the interbody space without instrumentation failure, as confirmed by the presence of continuous bridging bone observed on the lateral radiographs (Fig. 3). In the patient who had a broken pedicle screw, this was considered to be a pseudarthrosis. The mean breadth of the bridging bone also appeared to widen with time, although admittedly this is an inherently unreliable finding because each radiograph is not consistently obtained in an exact lateral projection. A sentinel sign, however, was present in only $10(25.6 \%)$ of 39 levels, which is consistent with other series. ${ }^{24}$

\section{Findings on CT Scans}

The CT scans in which sagittal and coronal 3D reconstruction was used were evaluated for bridging bone in the

TABLE 3

Reported complication rate for TLIF procedures in 191 patients*

\begin{tabular}{ll}
\hline \hline Complication & No. of Patients $(\%)$ \\
\hline dural tear & $9(4.7)$ \\
nonunion & $6(3.1)$ \\
implant breakage & $4(2.1)$ \\
nerve root injury & $3(1.6)$ \\
thrombophlebitis & $2(1.0)$ \\
implant loosening & $2(1.0)$ \\
pulmonary embolism & $1(0.5)$ \\
vascular injury & $0(0.0)$ \\
\hline
\end{tabular}

* According to a study by Harms and Jeszenszky. 


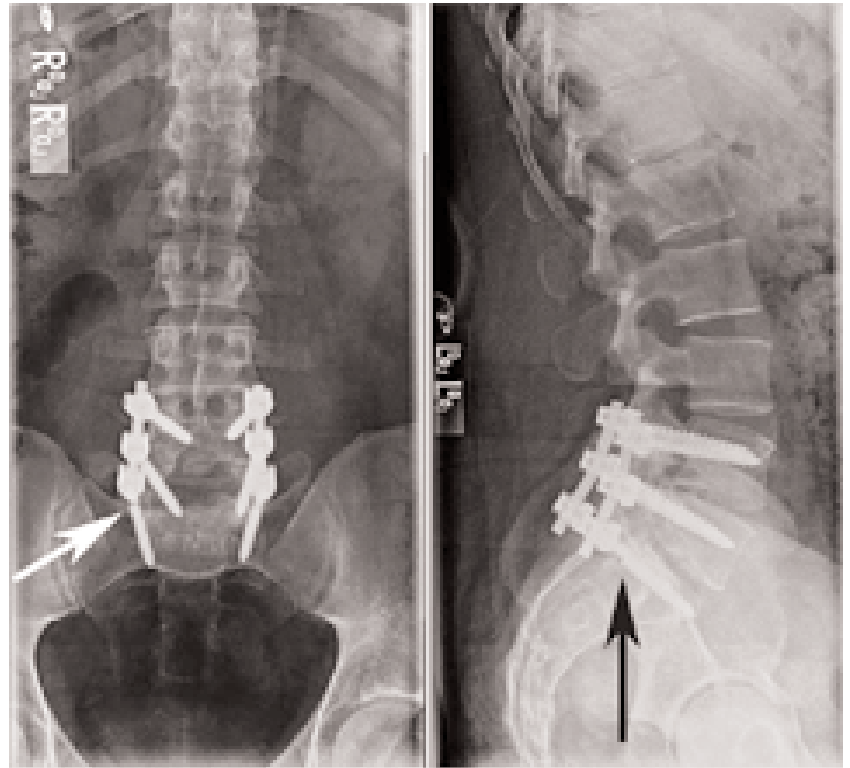

Fig. 2. Postoperative anteroposterior (left) and lateral (right) CT scans revealing a broken S-1 screw (arrows).

interbody space, as well as evidence of dislodgment, subsidence, and/or sterile abscess or reactive zone around the implant. Bridging bone was noted as early as the 3-month postoperative CT scan when obtained; however, this was not considered robust (Fig. 4). At the last follow-up visit, a continuous bridging bone was noted in 38 (97.4\%) of 39 fusion levels. On coronal scans, this typically measured 6 to $9 \mathrm{~mm}$ in width per cage, consistent with the internal diameter of an 11- or 13-mm cage minus the 2-mm cage wall thickness. For the several patients with repeated

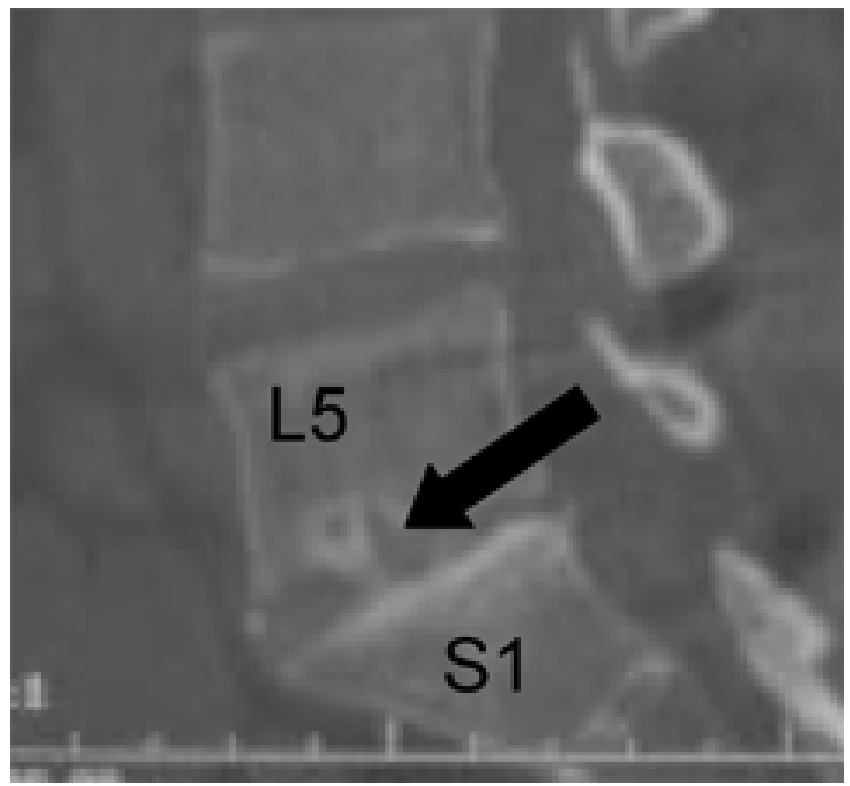

Fig. 3. Sagittal 3D CT scan demonstrating early bone column (6 months postoperatively) after an L5-S1 TLIF procedure. scans, the fusion mass appeared to increase in width after 1 year of follow up.

The cages were easily identified on coronal images, but became less distinct on follow-up scans. On sagittal 3D reconstructions, there often appeared to be a small area of radiolucency at the caudad and cephalad ends of the implant; however, this was not directly measured when the plain radiographs were evaluated for settling of the implant. We believe that this finding is real, but minimal, as noted on the lateral radiographs. This may represent a fibrous margin that is present all around the implant. ${ }^{24}$ There were no instances of a destructive inflammatory reaction or sterile abscess formation.

For those patients who underwent repeated scanning, the fusion mass appeared to increase with time, whereas the disc space height remained stable. Additionally, other authors have found similar results with the use of BMP, increasing the rate of interbody fusion over time. ${ }^{7}$

\section{DISCUSSION}

The science of bioabsorbable implants continues to evolve as clinical evidence grows. This series is one such study, in which the early surgical and clinical results are available.

\section{Postoperative Complications}

With newer generation of composite polymers, early concerns about sterile abscess or sinus tract formation, osteolysis, allergic reactions, or hypertrophic fibrous encapsulation have been almost eliminated. ${ }^{2-4,20}$ This has occurred because of the use of poly-L-lactic acid stereoisomers. ${ }^{22}$ Consequently, the incidence of infection appears to be low, and is probably consistent with allograft or titanium interbody spacers (unpublished data). In our series there were no superficial or deep infections at a mean follow-up duration of 12.4 months. A quiescent fibrous tissue layer containing dispersed foreign body giant cells, however, has been noted in animal studies ${ }^{24}$ and this also appears to be consistent with our postoperative CT scanning. Nonetheless, no device-related complications were noted.

\section{Radiographic Findings}

The radiographic fusion rate was $87.2 \%$ (34 of $39 \mathrm{fu}-$ sion levels) at a mean of 12.4 months of follow up, and there was evidence of one instrumentation failure. This is consistent with other studies, in which radiographs have been used to determine fusion success. ${ }^{15,16,18,23}$ Although plain radiographs are considered to be inherently unreliable for assessments of fusion status, bridging bone was conclusively identified on the majority of radiographic images. On 3D CT reconstruction scanning, the fusion rate was considered to be $97.3 \%$ (100\% for single-level fusions, eight cases). This is considerably better than in most series, as has been noted in multiple studies in the literature (mean $92 \%$ fusion success for single-level and $76 \%$ fusion success for two-level fusions). Notably, it is lower than the $98.9 \%$ overall fusion rate and the $100 \%$ fusion rate in two-, three-, and four-level PLIFs report by Brantigan, et al. ${ }^{6}$ 

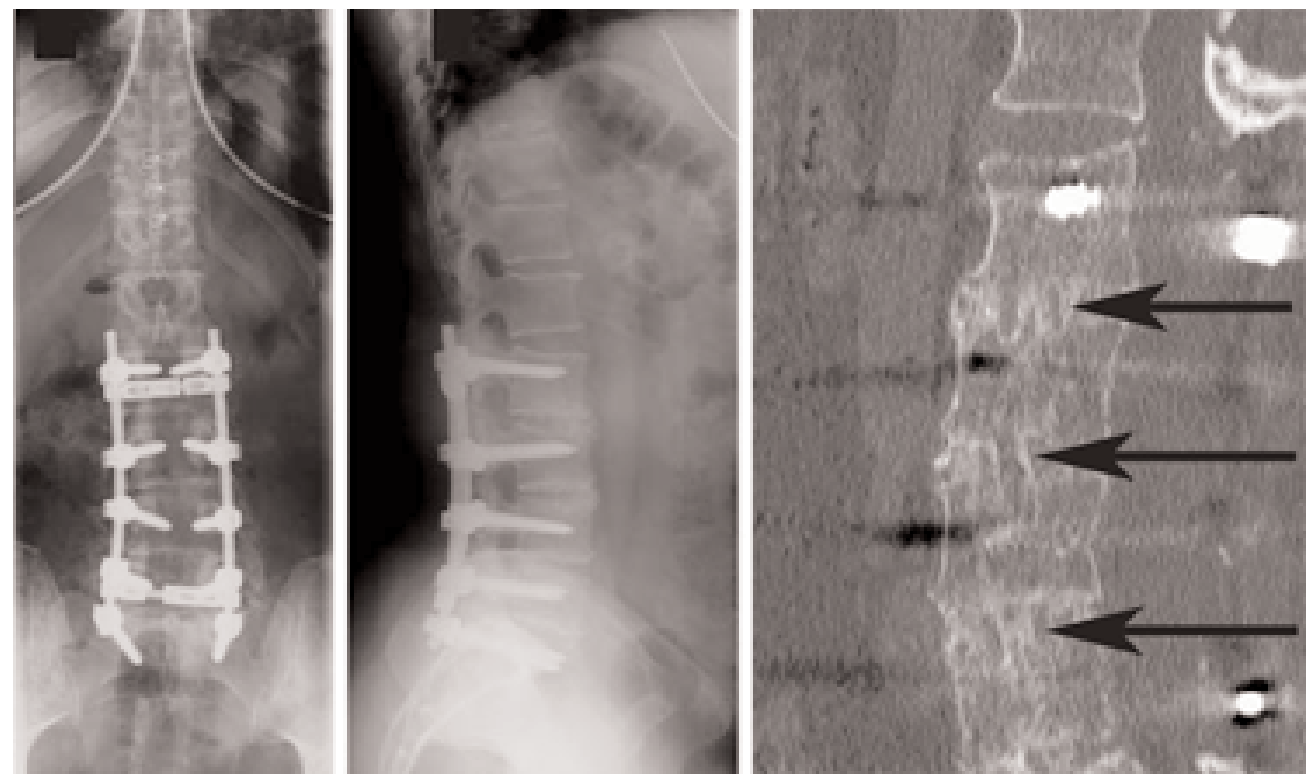

Fig. 4. Postoperative radiological studies obtained in a 59-year-old woman after a five-level fusion for degenerative disc disease with mild spinal stenosis. Anteroposterior (left) and lateral (center) postoperative radiographs and sagittal 3D CT scan (right) obtained at 18 months, demonstrating excellent interbody fusion with bone columns (arrows) at the site of HYDROSORB cages packed with rhBMP-2 at each level.

Perhaps more importantly, there appears to be a fusion mass buttressing effect, which occurs in the bioabsorbable cages packed with rhBMP-2. This is most likely caused by the time-patterned resorption and controlled "dynamization" of the resorbable cage. Ideally, the fusion mass would have to be solid by 18 months, because the cage resorption is complete by 18 to 36 months. If buttressing does not occur, then perhaps an inadequate fusion mass will eventually fail with increased activity, or more likely the instrumentation will fail.

Investigators have found that a cross-sectional area of $30 \%$ is needed to achieve a solid interbody arthrodesis. ${ }^{10}$ Because our study involves early findings (mean 12.4 months of follow up), this has not been noted. In the case of the broken screw, the 1-year follow-up CT scans revealed a solid arthrodesis. Perhaps this is an example of uncontrolled resorption or dynamization; nonetheless, the patient fortunately attained fusion and is currently asymptomatic.

\section{CONCLUSIONS}

Bioabsorbable interbody spacers do not appear to lead to an increased incidence of complications, and they appear to possess ideal interbody fusion characteristics because their slow resorption, compatibility with postoperative imaging, and gradual transfer of anatomical loads to the developing fusion mass. Postoperative fusion success is excellent, as confirmed on CT scanning. The devices reported in this series are not approved by the Food and Drug Administration for use in the spine. These devices have been cleared by the Food and Drug Administration, however, to maintain the relative position of weak bone tissue in trauma and reconstructive orthopedic procedures when they are used in conjunction with traditional rigid fixation.

\section{References}

1. Alexander JT, Branch CL Jr, Subach BR, et al: Applications of a resorbable interbody spacer via a posterior lumbar interbody fusion technique. Orthopedics 25 (Suppl 10):S1185-S1189, 2002

2. Bergsma EJ, Rozema FR, Bos RR, et al: Foreign body reactions to resorbable poly(L-lactide) bone plates and screws used for the fixation of unstable zygomatic fractures. J Oral Maxillofac Surg 51:666-670, 1993

3. Bergsma JE, de Bruijn WC, Rozema FR, et al: Late degradation tissue response to poly(L-lactide) bone plates and screws. Biomaterials 16:25-31, 1995

4. Bostman O, Hirvensalo E, Makinen J, et al: Foreign-body reactions to fracture fixation implants of biodegradable synthetic polymers. J Bone Joint Surg Br 72:592-596, 1990

5. Bostman OM, Pihlajamaki HK: Late foreign-body reaction to an intraosseous bioabsorbable polylactic acid screw. A case report. J Bone Joint Surg Am 80:1791-1794, 1998

6. Brantigan JW, Steffee AD, Lewis ML, et al: Lumbar interbody fusion using the Brantigan $\mathrm{I} / \mathrm{F}$ cage for posterior lumbar interbody fusion and the variable pedicle screw placement system: two-year results from a Food and Drug Administration investigational device exemption clinical trial. Spine 25:1437-1446, 2000

7. Burkus JK, Dorchak JD, Sanders DL: Radiographic assessment of interbody fusion using recombinant human bone morphogenetic protein type 2. Spine 28:372-377, 2003

8. Ciccone WJ II, Motz C, Bentley C, et al: Bioabsorbable implants in orthopaedics: new developments and clinical applications. J Am Acad Orthop Surg 9:280-288, 2001

9. Claes LE, Ignatius AA, Rehm KE, et al: New bioresorbable pin for the reduction of bony fragments: design, mechanical properties and in vitro degradation. Biomaterials 17:1621-1626, 1996

10. Closkey RF, Parsons JR, Lee CK, et al: Mechanics of interbody spinal fusion. Analysis of critical bone graft area. Spine 18: 1011-1015, 1993

11. Cornwall GB, Thomas KA, McManus AJ, et al: Compressive strength retention of 70:30 poly(L-lactide-co-D,L-lactide) fol- 
lowing real time ageing, in Society for Biomaterials 29th Annual Meeting Transactions. Minneapolis: Society for Biomaterials, 2003, p 393 (Abstract)

12. Govender S, Csimma C, Genant HK, et al: Recombinant human bone morphogenetic protein-2 for treatment of open tibial fracture: a prospective, controlled, randomized study of four hundred and fifty patients. J Bone Joint Surg Am 84:2123-2134, 2002

13. Harms J, Jeszenszky D: The unilateral transforaminal approach for posterior lumbar interbody fusion. Orthop Traumatol 6: 88-99, 1998 (Reference unverified)

14. Kohn J, Langer R: Bioresorbable and bioerodible materials, in Ratner BD, Hoffman AS, Schoen FJ, et al (eds): Biomaterials Science: An Introduction to Materials in Medicine. San Diego: Academic Press, 1996, pp 64-73

15. Kuslich SD, Ulstrom CL, Griffith SL, et al: The Bagby and Kuslich method of lumbar interbody fusion. History, techniques, and 2-year follow-up results of a United States prospective, multicenter trial. Spine 23:1267-1279, 1998

16. McAfee PC, Regan JJ, Geis WP, et al: Minimally invasive anterior retroperitoneal approach to the lumbar spine. Emphasis on the lateral BAK. Spine 23:1476-1484, 1998

17. Polly DW Jr, Ackerman SJ, Shaffrey CI, et al: A cost analysis of bone morphogenic protein versus autogenous iliac crest bone graft in single-level anterior lumbar fusion. Orthopaedics 26: 1027-1037, 2003

18. Ray CD: Threaded titanium cages for lumbar interbody fusions. Spine 22:667-680, 1997

19. Sandhu HS, Toth JM, Diwan AD, et al: Histologic evaluation of
T. R. Kuklo, M. K. Rosner, and D. W. Polly, Jr.

the efficacy of rhBMP-2 compared with autograft bone in sheep spinal anterior interbody fusion. Spine 27:567-575, 2002

20. Tegnander A, Engebretsen L, Bergh K, et al: Activation of the complement system and adverse effects of biodegradable pins of polylactic acid (Biofix) in osteochondritis dissecans. Acta Orthop Scand 65:472-475, 1994

21. Toth JM, Wang M, Scifert JL, et al: Evaluation of 70/30 D,LPla for use as a resorbable interbody fusion cage. Orthopedics 25 (Suppl 10):S1131-S1140, 2002

22. Vaccaro AR, Singh K, Haid R, et al: The use of bioabsorbable implants in the spine. Spine J 3:227-237, 2003

23. Whitecloud TS III, Castro FP Jr, Brinker MR, et al: Degenerative conditions of the lumbar spine treated with intervertebral titanium cages and posterior instrumentation for circumferential fusion. J Spinal Disord 11:479-486, 1998

24. Wuisman PJ, van Dijk M, Smit TH: Resorbable cages for spinal fusion: an experimental goat model. Orthopedics 25 (Suppl 10):S1141-S1148, 2002

Manuscript received January 15, 2004.

Accepted in final form February 15, 2004.

The opinions or assertions contained herein are the private views of the authors and are not to be construed as official or as reflecting the views of the US Army or the Department of Defense.

Address reprint requests to: LTC(P) Timothy R. Kuklo, M.D., Department of Orthopaedics and Rehabilitation, Walter Reed Army Medical Center, 6900 Georgia Avenue, Washington, DC 20307. email: Timothy.Kuklo@na.amedd.army.mil. 